\title{
IgA response in serum and gut secretion in sensitized mice fed with the dust mite Dermatophagoides pteronyssinus extract
}

M. Maciel, A.E. Fusaro,

C.R. Oliveira, E.A. Futata,

A.J.S. Duarte and M.N. Sato
Laboratório de Alergia e Imunologia Clínica e Experimental (LIM-56),

Faculdade de Medicina, Universidade de São Paulo, São Paulo, SP, Brasil
Correspondence

M.N. Sato

Laboratório de Alergia e Imunologia

Clínica e Experimental, LIM-56

Faculdade de Medicina, USP

Av. Dr. Arnaldo, 455

20 andar, Sala 2345

01246-903 São Paulo, SP

Brasil

Fax: +55-11-3081-7190

E-mail: marisato@usp.br

Research supported by FAPESP (No. 99/11496-8) and LIM-56, HC/FMUSP.

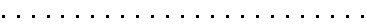

Received January 14, 2003 Accepted February 18, 2004

\begin{abstract}
Induced oral tolerance to mucosal-exposed antigens in immunized animals is of particular interest for the development of immunotherapeutic approaches to human allergic diseases. This is a unique feature of mucosal surfaces which represent the main contact interface with the external environment. However, the influence of oral tolerance on specific and natural polyreactive IgA antibodies, the major defense mechanism of the mucosa, is unknown. We have shown that oral administration of an extract of the dust mite Dermatophagoides pteronyssinus $(\mathrm{Dp})$ to primed mice caused down-regulation of $\mathrm{IgE}$ responses and an increase in tumor growth factor- $\beta$ secretion. In the present study, we observed that primed inbred female $\mathrm{A} / \mathrm{Sn}$ mice ( 8 to 10 weeks old) fed by gavage a total weight of $1.0-\mathrm{mg}$ Dp extract on the 6th, 7th and 8th days post-immunization presented normal secretion of IL-4 and IL-10 in gut-associated lymphoid tissue and a decreased production of interferon gamma induced by $\mathrm{Dp}$ in the draining lymph nodes $(13,340 \pm 3,519$ vs 29,280 $\pm 2,971 \mathrm{pg} / \mathrm{ml})$. Mice fed the $\mathrm{Dp}$ extract also showed higher levels of serum anti-Dp IgA antibodies and an increase of IgA-secreting cells in mesenteric lymph nodes $(\mathrm{N}=10)$, reflecting an increase in total fecal IgA antibodies $(\mathrm{N}=10)$. The levels of secretory anti-Dp IgA antibodies increased after re-immunization regardless of Dp extract feeding. Oral tolerance did not interfere with serum or secretory IgA antibody reactivity related to self and non-self antigens. These results suggest that induction of oral tolerance to a Dp extract in sensitized mice triggered different regulatory mechanisms which inhibited the IgE response and stimulated systemic and secretory $\operatorname{Ig} \mathrm{A}$ responses, preserving the natural polyreactive $\operatorname{IgA}$ antibody production.
\end{abstract}

\section{Introduction}

IgA antibodies play an essential role in mucosal protection. The ability to be secreted when linked to secretory components,
Key words

- Mucosa

- Natural IgA antibodies

- Oral tolerance

- Cytokines

- Allergy

- Dermatophagoides

pteronyssinus 
ruses and bacteria from epithelia, preventing their adhesion and subsequent infection (2). On this basis, immune strategies to elicit the production of IgA antibodies at the mucosal level are desirable in vaccine approaches. The broad function of IgA antibodies may be due to their polyreactivity (3). Furthermore, immunoglobulins of the IgA, IgM and IgG isotypes may work as polyreactive receptors able to interact with self and non-self antigens, such as DNA, collagen, interferons (IFN), tumor necrosis factor, insulin and cholesterol and can exert a physiological regulatory role $(2,4,5)$.

Natural polyreactive IgA antibodies produced by mucosal plasma cells contribute to the maintenance of gut homeostasis by detecting invasion by pathogenic microorganisms and controlling immune responses in the gut (6). Most of the production of intestinal polyreactive IgA antibodies is ascribed to B-1 cells, which are present in gut mucosae as lamina propria lymphocytes (7). Another subset of IgA-secreting cells originates from precursor cells present in Peyer's patches, mainly with the B-2 phenotype (8). After antigenic stimulation, B-2 lymphocytes migrate from Peyer's patches to mesenteric lymph nodes, enter the thoracic duct, mature, and return to mucosal sites (9).

Antigen delivery on mucosal surfaces may induce either immunization or unresponsiveness. Oral tolerance, as usually defined, is the suppression of humoral and cellular immune responses after mucosal presentation of a putative protein antigen (10). We have reported that induction of oral tolerance in a murine model of hypersensitivity to the dust mite Dermatophagoides pteronyssinus $(\mathrm{Dp})$ down-modulated the Th2 response and decreased both the number of IgE-secreting cells and specific $\operatorname{IgE}$, and $\operatorname{IgG}$ antibody production (11). It has been reported that an increase in specific IgA antibodies occurs concomitantly with the systemic suppression induced by oral tolerance (12). However, it is unknown whether anti- gen feeding can modulate the systemic and mucosal response in primed mice, and there are no data about the influence of antigens on polyreactive IgA antibody production.

We investigated the profile of the IgA antibody response in mice sensitized to the Dp extract and subjected to an oral antigen administration protocol. Oral administration of the Dp extract increased serum specific IgA antibody levels and the number of IgAsecreting cells in the mesenteric lymph nodes, whereas it down-modulated IFN gamma (IFN- $\gamma$ ) secretion in peripheral lymph nodes. Oral administration of the Dp extract stimulated total IgA antibody production at the mucosal level, maintaining the balance of natural polyreactive IgA antibodies.

\section{Material and Methods}

\section{Animals}

Inbred female $\mathrm{A} / \mathrm{Sn}$ mice ( 8 to 10 weeks old) were supplied by the animal facility of the University of São Paulo - School of Medicine. Wistar Furth rats (RT1 $\left.{ }^{\mathrm{u}, \mathrm{u}}\right)$ of both sexes, 3-4 months old, bred in our own animal facility, were used for passive cutaneous anaphylaxis (PCA) reaction.

\section{Immunization and oral administration of Dermatophagoides pteronyssinus extract}

The mice were sensitized subcutaneously at the tail base and intramuscularly in both hind footpads with a total of $10 \mu \mathrm{g}$ Dp extract (Ifidesa-Aristegui, Bilbao, Spain; 112,900 units biological equivalents $/ \mathrm{ml}$; protein content: $1,016 \mathrm{mg} / \mathrm{ml}$; containing $49.9 \%$ of the major allergens), emulsified $\mathrm{v} / \mathrm{v}$ with complete Freund's adjuvant (CFA; Sigma, St. Louis, MO, USA; Figure 1). The animals received two intraperitoneal (ip) boosters on the $21 \mathrm{st}(10 \mu \mathrm{g})$ and $28 \mathrm{th}(50 \mu \mathrm{g})$ days postimmunization (dpi). Under light ether anesthesia, mice were fed by gavage a total of 1.0 $\mathrm{mg} \mathrm{Dp}$ extract dissolved in $0.5 \mathrm{ml}$ saline, on 
the 6th, 7th, and 8th dpi. The control group was similarly fed saline solution. Each mouse was bled on the 21st, 28th and 35th dpi by the retro-orbital plexus and individually collected sera were frozen at $-20^{\circ} \mathrm{C}$ until use.

\section{Passive cutaneous anaphylaxis}

IgE antibodies were estimated by the PCA reaction as described by Mota and Wong (13). Diluted mouse serum samples $(0.1 \mathrm{ml})$ were inoculated intradermally into the shaved back of rats. After $18 \mathrm{~h}$, the rats received 0.5 $\mathrm{mg}$ Dp extract in $1.0 \mathrm{ml} 0.5 \%$ Evans blue by tail vein injection and were sacrificed $1 \mathrm{~h}$ later. The highest reciprocal serum dilution presenting a spot of more than $5 \mathrm{~mm}$ in diameter was taken as the PCA titer.

\section{Fecal pellet extract collection}

Fresh fecal pellets from normal mice and from Dp extract- and saline-fed mice were collected into microtubes on the 9th and 28th dpi and weighed. Phosphate-buffered saline (PBS) was added at a ratio of $1 \mathrm{ml} / 100$ $\mathrm{mg}$ fecal pellets. The material was vortexed for $5 \mathrm{~min}$ at room temperature according to the method described by Bao et al. (14). The tubes were centrifuged at $3000 \mathrm{~g}$ for $10 \mathrm{~min}$ and the supernatants were transferred to tubes containing $10 \mu \mathrm{l}$ of protease inhibitor cocktail (4-(2 aminoethyl)benzenesulfonyl fluoride, trans-epoxysuccinyl-leucyl-amido (4 guanidino) butane (E-64), bestatin, leupeptin, aprotinin, and sodium EDTA; Sigma) and briefly vortexed. Individual samples were

stored at $-20^{\circ} \mathrm{C}$ until the time for assay.

\section{Cytokine measurements in the supernatant of lymphocyte cultures}

Mesenteric lymph nodes (MLN), peripheral lymph nodes (periaortic and inguinal lymph nodes, PLN) and Peyer's patches (PP) were removed aseptically from the mice on the 12th dpi, collected into RPMI 1640 medium (Gibco, Laboratories, Detroit, MI, USA) and pressed through a stainless steel wire mesh to produce a single cell suspension. After three washes with medium, cells were resuspended in RPMI 1640 medium supplemented with $10 \%$ fetal calf serum (FCS) (Hyclone Laboratories, Inc., Logan, UT, USA), $40 \mathrm{mg} / 1$ gentamicin and $200 \mathrm{U} / 1$ penicillin.

The single PP, MLN, or PLN cell suspensions $\left(10 \times 10^{6}\right.$ cells $\left./ \mathrm{ml}\right)$ were cultured in the presence of Dp extract $(50 \mu \mathrm{g} / \mathrm{ml})$, concanavalin A (Con A; $5 \mu \mathrm{g} / \mathrm{ml}$ ), or medium alone for $24 \mathrm{~h}$ (for interleukin (IL)-4 detection) or $72 \mathrm{~h}$ (for IFN- $\gamma$ and IL-10 detection) at $37^{\circ} \mathrm{C}$, in the presence of $5 \% \mathrm{CO}_{2}$, whereupon cell-free supernatants were collected and stored at $-20^{\circ} \mathrm{C}$ until the time for assay.

The supernatants were assayed using the cytokine-specific enzyme immunoassay (EIA) to detect IFN- $\gamma$, IL-4 (Minikits, Endogen, Woburn, MA, USA), and IL-10 (Duo set, Genzyme, Cambridge, MA, USA). The tests were performed according to the manufacturer's instructions. The detection limit levels for IL-4, IL-10, and IFN- $\gamma$ were 4 $\mathrm{pg} / \mathrm{ml}, 60 \mathrm{pg} / \mathrm{ml}$, and $0.48 \mathrm{ng} / \mathrm{ml}$, respectively.

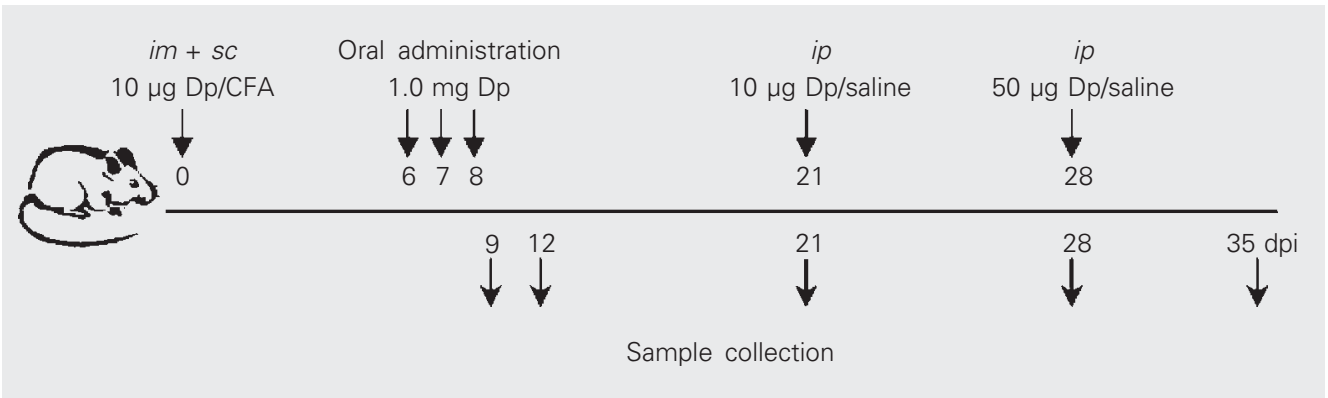

Figure 1. Immunization schedule of Dermatophagoides pteronyssinus (Dp) extract and oral administration to mice. Samples (cells, sera and fecal extracts) were obtained at different times after immunization with the Dp (see Material and Methods). CFA $=$ complete Freund's adjuvant; $\mathrm{dpi}=$ days post-immunization. 
Enzyme immunoassays for total and specific antibodies

In order to measure anti-Dp IgA antibodies by EIA, 96-well microplates (high binding; Costar, Cambridge, MA, USA) were coated with $5 \mu \mathrm{g} / \mathrm{ml} \mathrm{Dp}$ extract in $0.1 \mathrm{M}$ carbonate-bicarbonate buffer, $\mathrm{pH}$ 9.5. Before incubation of the serum sample dilutions the wells were blocked with PBS containing $0.5 \%$ gelatin. Detection was performed with biotinylated anti- $\alpha$ mouse chain antibodies (1:1000; Southern Biotechnology Associates, Inc., Birmingham, AL, USA) and streptavidin $\beta$-galactosidase (1:1500; Sigma), followed by ortho-nitrophenyl- $\beta-D-$ galactopyranoside (Sigma), $0.8 \mathrm{mg} / \mathrm{ml}$ in 0.1 $\mathrm{M}$ phosphate buffer, $\mathrm{pH}$ 7.0, containing $0.0056 \%(\mathrm{v} / \mathrm{v})$ 2-ß-mercaptoethanol. The reaction was read at $415 \mathrm{~nm}$ with microplate reader (Bio-Rad Laboratories, Hercules, CA, USA).

To measure the concentration of total $\operatorname{IgA}$ and $\operatorname{IgG}$ antibodies, 96-well microplates (high binding) were coated with $2.5 \mu \mathrm{g} / \mathrm{ml}$ anti- $\alpha$ or anti- $\gamma$ mouse chain in $0.1 \mathrm{M}$ carbonate-bicarbonate buffer, $\mathrm{pH}$ 9.5. The wells were blocked with PBS containing 1\% bovine serum albumin (BSA; Sigma) before incubation of the serum sample dilutions. Biotinylated anti- $\alpha$ or anti- $\gamma$ (Southern Biotechnology) antibody was added at 1:1000 and 1:3000, respectively, and incubated for $1 \mathrm{~h}$ at $37^{\circ} \mathrm{C}$. After washes, streptavidin-peroxidase (Sigma) was added for $35 \mathrm{~min}$ at $37^{\circ} \mathrm{C}$ and the reaction was developed by the addition of 3,3',5,5'-tetramethyl-benzidine (Sigma). Sulfuric acid was used to stop the reaction, which was read at $450 \mathrm{~nm}$. The absorbance was correlated to known amounts of purified protein standards.

To analyze IgA polyreactivity in serum and fecal samples, the following antigens were used: IgE (anti-Dansyl, $\kappa$ chain, specific for the hapten 5-dimethylaminonaphthalene-1-sulfonyl; Pharmingen, San Diego, CA, USA), ovalbumin (OVA), hen egg lysozyme
(HEL), lipopolysaccharide (LPS), phosphorylcholine (PC)-BSA, and ssDNA purchased from Sigma. The anti-IgE IgG reactivity was also investigated. Ninety-six-well microplates (high binding) were coated with $2.5 \mu \mathrm{g} / \mathrm{ml}$ of each antigen in $0.1 \mathrm{M}$ carbonate-bicarbonate buffer, $\mathrm{pH} 9.5$, overnight at $4^{\circ} \mathrm{C}$. Washes with PBS were performed and several dilutions of the sera and fecal samples were incubated for $1 \mathrm{~h}$ at $37^{\circ} \mathrm{C}$, and overnight at $4^{\circ} \mathrm{C}$. After the washes, biotinylated anti- $\alpha$ antibody was added at the dilution of 1:1000 for IgA polyreactivity evaluation and biotinylated anti-Fcy (Sigma) was added at the dilution of 1:3000 for anti-IgE IgG assays, followed by incubation for $1 \mathrm{~h}$ at $37^{\circ} \mathrm{C}$. After new washes, streptavidin-peroxidase was added for $35 \mathrm{~min}$ and incubated at $37^{\circ} \mathrm{C}$, and the reaction was developed as described above.

\section{Elispot assay for the estimation of IgA-secreting cells in gut-associated lymphoid tissue}

In order to measure the number of total IgA-secreting cells in PP and MLN, 96-well flat-bottom microplates (Costar) were coated with $5 \mu \mathrm{g} / \mathrm{ml}$ anti- $\alpha$ chain antibody in $0.1 \mathrm{M}$ carbonate-bicarbonate buffer, $\mathrm{pH}$ 9.5, and incubated overnight. After the PBS washes, the wells were blocked with PBS containing $2 \%$ BSA for $2 \mathrm{~h}$. Serial dilutions of cell suspensions in RPMI 1640 medium supplemented with $10 \%$ FCS were added, starting with $25 \times 10^{4}$ cells, in volumes of $200 \mu \mathrm{l}$ per well. The plates were incubated for $18 \mathrm{~h}$ at $37^{\circ} \mathrm{C}$ in the presence of $5 \% \mathrm{CO}_{2}$. After four washes with PBS containing $0.01 \%$-Tween 20, biotinylated anti-IgA antibody (1:750; Southern Biotechnology) was added and plates were incubated overnight at $4^{\circ} \mathrm{C}$. After a similar washing procedure streptavidinalkaline phosphatase (1:1000; Southern Biotechnology) was added and the plates were incubated for $2 \mathrm{~h}$ at room temperature. The reaction was developed by the addition of 
5-bromo-4-chloro-3-indolyl phosphate (Sigma), $50 \mu \mathrm{l} /$ well and incubation for $2 \mathrm{~h}$ at $37^{\circ} \mathrm{C}$. Washes with distilled water were used to stop the reaction. Spot reading was performed with an inverted microscope and the number of IgA-secreting cells is reported per $10^{4}$ cells.

\section{Statistical analysis}

Data were analyzed statistically by the unpaired Student $t$-test, with the level of significance set at $\mathrm{P}<0.05$.

\section{Results}

In vitro cytokine secretion in sensitized mice fed a Dermatophagoides pteronyssinus extract

Groups of $\mathrm{A} / \mathrm{Sn}$ mice were sensitized with the Dp extract emulsified in CFA and fed the extract for three consecutive days according to the scheme in Figure 1. After two ip boosters on the 28th and 35th dpi, specific IgE antibodies were assayed by PCA. Oral administration of the Dp extract to sensitized mice induced a significant decrease in specific $\operatorname{IgE}$ antibody levels compared to mice fed saline $(1: 160 v s 1: 40, \mathrm{P}<0.05$; data not shown), confirming previous findings (11).

Figure 2 shows that the IFN- $\gamma$ secretion by PLN cells collected on the 12th dpi and stimulated with the Dp extract and Con A was significantly decreased in mice fed the Dp extract compared to saline-fed mice. However, when compared to MLN and PP cells, PLN cells were able to secrete IFN- $\gamma$ at higher levels after both stimuli. These observations did not differ significantly between mice fed the Dp extract and saline-fed mice. MLN cells secreted high IL-4 levels when induced by $\mathrm{Con} \mathrm{A}$, in contrast to the scarce
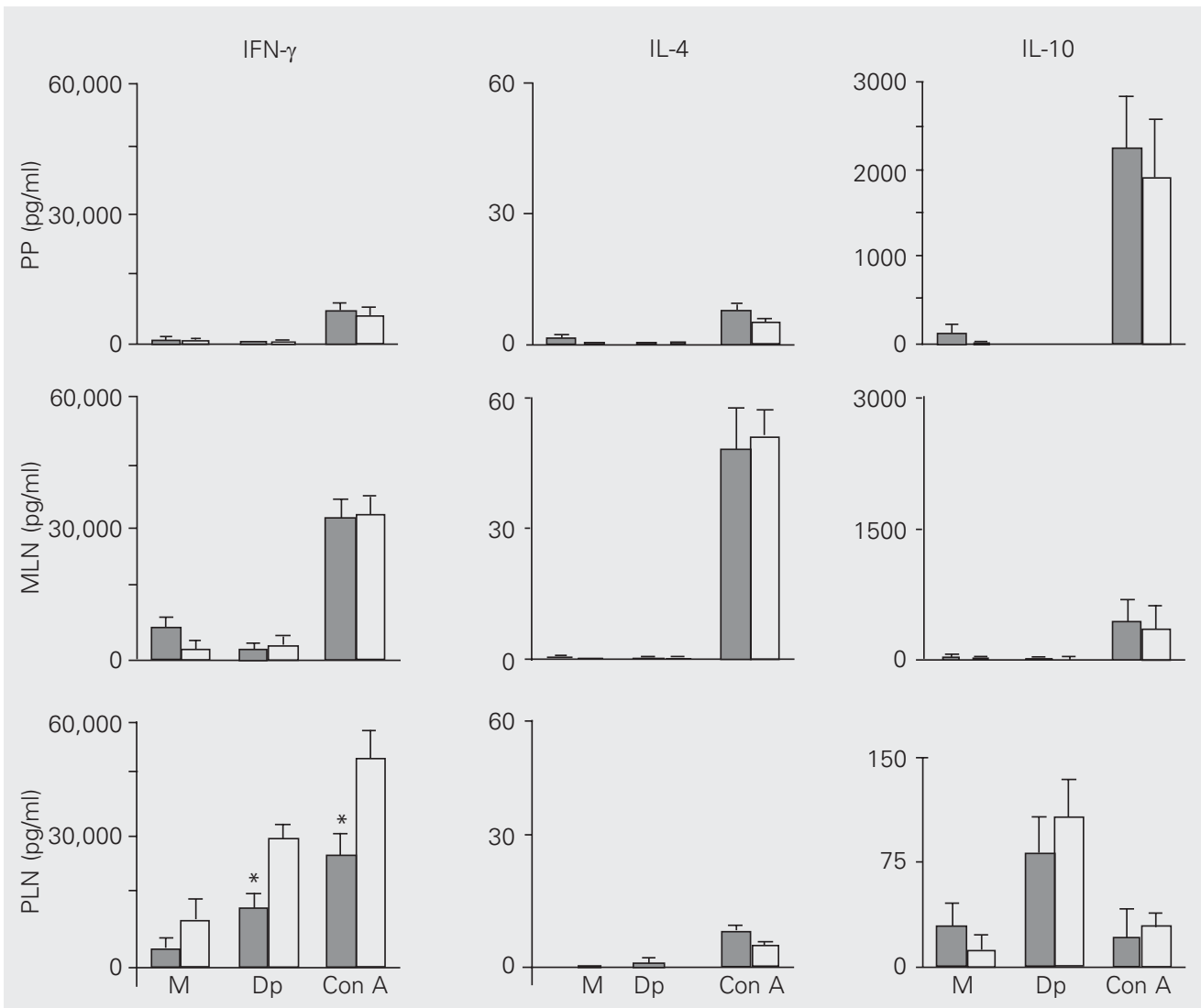

Figure 2. Profile of in vitro cytokine secretion by Peyer's patch (PP), mesenteric lymph node (MLN), and peripheral lymph node (PLN) cells from previously sensitized mice fed a Dermatophagoides pteronyssinus (Dp) extract. Mice were fed either the Dp extract (closed bars) or saline (open bars) on the 6th, 7th and 8th days postimmunization (dpi). The PP, MLN and PLN cells were harvested on the 12th dpi and cultured in the presence of Dp extract $(50 \mu \mathrm{g} / \mathrm{ml})$, concanavalin $\mathrm{A}$ (Con $A, \mu g / m l)$, or medium (M) alone (baseline level). Supernatants obtained after $24 \mathrm{~h}$ were tested for interleukin (IL)-4, and supernatants obtained after 72 $\mathrm{h}$ were tested for interferon gamma (IFN- $\gamma$ ) and IL-10. Data are reported as means \pm SEM for 3 mice in each group of three individual experiments. ${ }^{*} P<$ 0.05 compared to saline-fed mice (unpaired Student t-test). 
amounts secreted after antigenic stimulation in all tissues analyzed. PLN cells produced increased IL-10 levels after specific antigen stimulation. Under mitogenic stimulation, PP and MLN cells secreted 20- and 80-fold more IL-10 than PLN cells, respectively.

Gut-associated lymphoid tissue IgA-secreting cells and serum and secretory anti-Dp IgA antibodies in sensitized mice fed the Dp extract

The number of IgA-secreting cells 4 days after oral administration of the Dp extract (12th dpi) was investigated in PP and MLN. The number of PP IgA-secreting cells was similar in both Dp extract- and saline-fed groups on the 12th dpi. At the same time, a significantly higher number of IgA-secreting cells was found in MLN of mice fed the Dp extract compared to saline-fed mice (Table 1). Both groups presented the same concentration of total IgA antibodies in fecal extracts soon after gavage (9th dpi), but a significant increase was found in mice fed the Dp extract compared to saline-fed mice on the 28th dpi. No differences in total $\operatorname{IgG}$ antibodies were observed in fecal extract samples from mice fed the Dp extract and from saline-fed mice at either time point. Interestingly, total IgA antibody concentrations in mice fed the Dp extract were 11-fold higher than total IgG antibodies on the 9th dpi, and 27-fold higher on the 28th dpi (Table 1).

There was a significant increase of serum anti-Dp IgA antibody levels after the first antigen booster in mice fed the Dp extract compared to saline-fed mice (Figure 3).

\section{Evidence for serum and secretory polyreactive IgA antibodies in sensitized mice fed the Dp extract}

Since oral administration of the Dp extract resulted in increased serum and fecal IgA response, and since IgA antibodies show a characteristic polyreactivity to self and non-self structures (6), the natural polyreactive IgA response was analyzed in mice fed the Dp extract. Some protein and non-protein molecules were chosen, which represent structures not related to Dp (OVA and HEL), self-molecules like DNA and IgE, or lipid molecules like LPS and PC, one of the major components of the gut bacterial flora.

In contrast to the increase of serum antiDp IgA antibodies found in mice fed the Dp extract, IgA antibody reactivity against most antigens of the panel did not change. Mice fed the Dp extract and saline-fed mice showed increased IgA reactivity against OVA when compared to normal mice (Figure 4).

Figure 5 shows that the oral administra-

\begin{tabular}{|c|c|c|c|c|c|c|}
\hline & \multicolumn{2}{|c|}{$\begin{array}{l}\text { IgA-secreting cells } \\
\left(/ 10^{4} \text { cells }\right)\end{array}$} & \multicolumn{2}{|c|}{$\begin{array}{l}\text { Total fecal lgA antibodies } \\
(\mu \mathrm{g} / \mathrm{ml})\end{array}$} & \multicolumn{2}{|c|}{$\begin{array}{c}\text { Total fecal lgG antibodies } \\
(\mu \mathrm{g} / \mathrm{ml})\end{array}$} \\
\hline & PP & MLN & 9th dpi & 28th dpi & 9th dpi & 28th dpi \\
\hline Normal mice & ND & ND & \multicolumn{2}{|c|}{$58.5 \pm 19.9$} & \multicolumn{2}{|c|}{$6.2 \pm 1.8$} \\
\hline Dp-fed mice & $179.1 \pm 28.9$ & $205.7 \pm 14.5^{*}$ & $68.5 \pm 7.7$ & $143.8 \pm 3.2^{*}$ & $6.2 \pm 1.0$ & $5.3 \pm 1.5$ \\
\hline Saline-fed mice & $221.0 \pm 0.8$ & $148.6 \pm 3.0$ & $68.5 \pm 7.5$ & $79.2 \pm 24.5$ & $5.1 \pm 0.7$ & $3.5 \pm 0.8$ \\
\hline
\end{tabular}


tion of Dp extract did not interfere with the secretory production of anti-Dp IgA antibodies, but seven days after the first booster, antibody levels increased 3-fold in mice fed the Dp extract and 4-fold in saline-fed mice, compared to the respective group on the 9th dpi. On the 28th dpi, a significant increase in secretory anti-OVA IgA antibodies was observed in mice fed the Dp extract compared to normal mice. A similar increase was observed in secretory anti-DNA IgA antibodies in mice fed the Dp extract compared to the saline-fed group. No significant differences in antibody levels were observed between the experimental and control groups regarding the IgA reactivity against HEL, LPS and PC.

In addition, we determined the reactivity of $\operatorname{IgA}$ and $\operatorname{IgG}$ antibodies to the IgE molecule in serum and fecal extracts on the 28th dpi. Similar reactivity patterns of serum and secretory anti-IgE IgA antibodies were observed in mice fed the Dp extract and salinefed mice, as well as in normal mice (Figure $6 \mathrm{~A})$. In contrast, the reactivity of serum antiIgE IgG antibody was significantly increased in mice fed the Dp extract and saline-fed mice compared to normal mice (Figure 6B). The level of anti-IgE IgG antibodies present in fecal extracts was diminished in mice fed the Dp extract and saline-fed mice compared to normal mice. Saline-fed mice showed even lower levels of anti-IgE IgG antibodies com-

Figure 5. Reactivity of secretory polyreactive IgA antibodies in sensitized mice fed a Dermatophagoides pteronyssinus (Dp) extract. Fecal pellets were collected from mice on the 9th and 28th days post-immunization (dpi) and extracts were obtained with PBS washes. Secretory IgA antibodies present in the samples were tested by ELISA against a panel of different self and non-self antigens, i.e., Dp extract, ovalbumin (OVA), hen egg lysozyme (HEL), lipopolysaccharide (LPS), phosphorylcholine (PC)-BSA, and SsDNA. Data are reported as means \pm SEM for 3-5 mice in each group of four independent experiments. ${ }^{*} \mathrm{P}<$ 0.05 compared to saline-fed mice; ${ }^{*} P<0.05$ compared to normal mice (unpaired Student $t$-test). pared to mice fed the Dp extract.

\section{Discussion}

Our previous results with oral tolerance

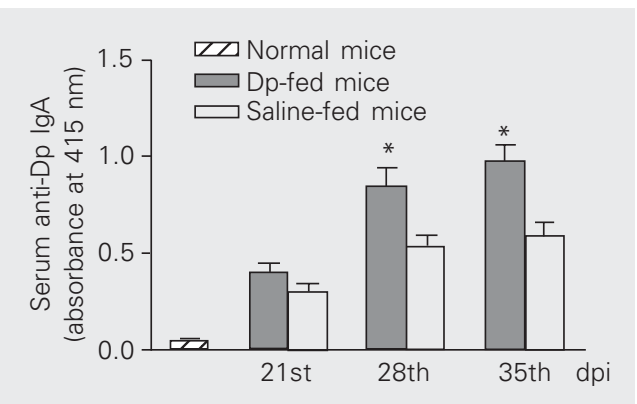

Figure 3. Serum anti-Dermatophagoides pteronyssinus (Dp) IgA antibody levels of previously sensitized mice fed the Dp extract. A/Sn mice were immunized with $\mathrm{Dp}$ extract-complete Freund's adjuvant, fed the Dp extract or saline on the 6th, 7th and 8th days post-immunization (dpi), and boosted on the 21 st and 28th dpi. The animals were bled on the 21st, 28th and 35th dpi and individual sera were assayed for anti-Dp IgA antibodies by ELISA. Data are reported as means \pm SEM for 4-7 mice in each group of four independent experiments. ${ }^{*} P<0.05$ compared to saline-fed mice (unpaired Student $t$-test).

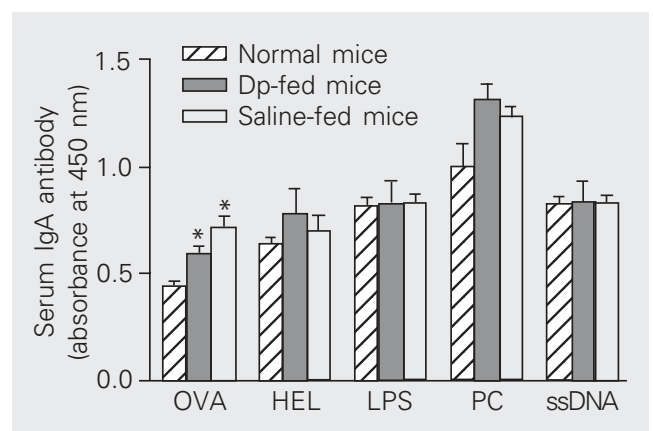

Figure 4. Reactivity of serum polyreactive IgA antibodies in sensitized mice fed a Dermatophagoides pteronyssinus (Dp) extract. IgA antibodies present in the sera obtained from Dp extract- and saline-fed mice on the 28th dpi were tested by ELISA against a panel of different antigens, i.e., ovalbumin (OVA), hen egg lysozyme (HEL), lipopolysaccharide (LPS), phosphorylcholine (PC), and ssDNA. Data are reported as means \pm SEM for 3-6 mice in each group of four independent experiments. ${ }^{*} \mathrm{P}<0.05$ when compared to normal mice (unpaired Student $t$-test).

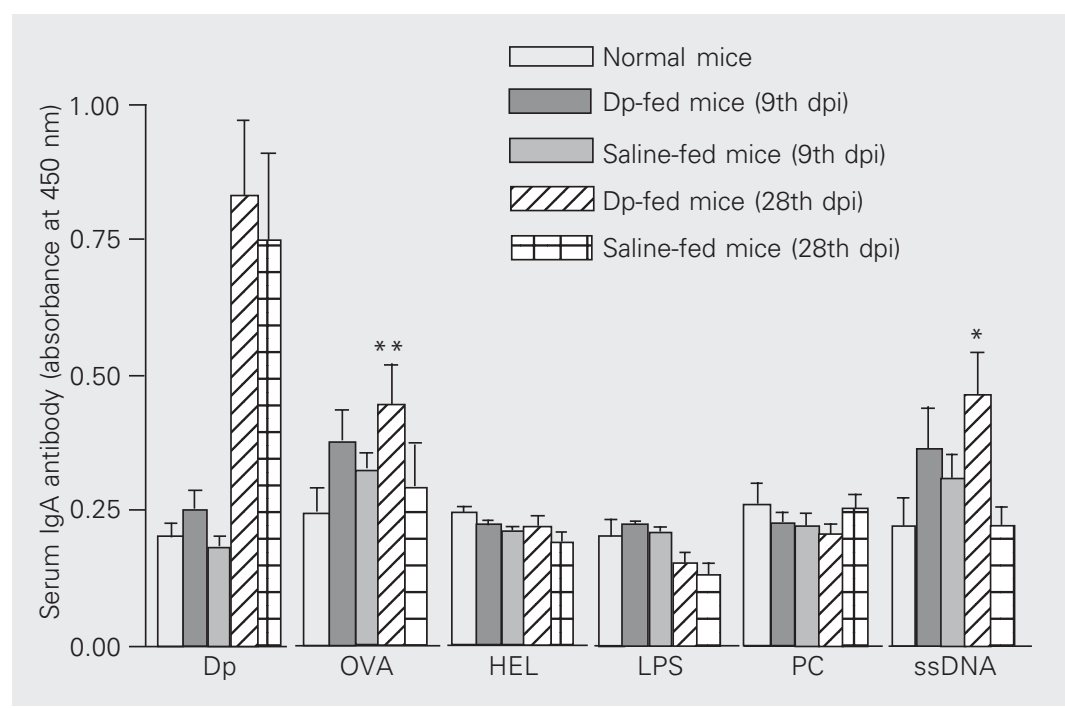


to the dust mite Dp extract in mice showed that oral administration down-modulated the Th2-axis, including IgE $(11,15), \operatorname{IgG} 1$ and IL-4 production and up-regulated TGF- $\beta$ secretion (16). However, the complex regulatory cytokine network triggered by oral tolerance, regarding the specific and natural polyreactive IgA response in the serum and gut secretion of allergen-tolerized mice is not completely understood.

We observed up-regulation of serum antiDp IgA antibodies in sensitized mice orally fed the Dp extract. These mice also showed a high frequency of IgA-secreting cells in mesenteric lymph nodes 4 days after $\mathrm{Dp}$ extract feeding. These results indicate that $\operatorname{IgA}^{+} \mathrm{B}$ cells may have been stimulated by antigen feeding and migrated through mesenteric lymph nodes, reaching the systemic circulation. Since Peyer's patches contain mostly B-2 cells that have the potential to secrete specific antibodies (8), they may have been responsible for the specific serum IgA response observed. Indeed, it is possible that some of these cells moved to the periphery and secreted specific IgA antibodies in response to the Dp extract boosters on the 28th and 35th dpi. Mucosal antigen delivery might

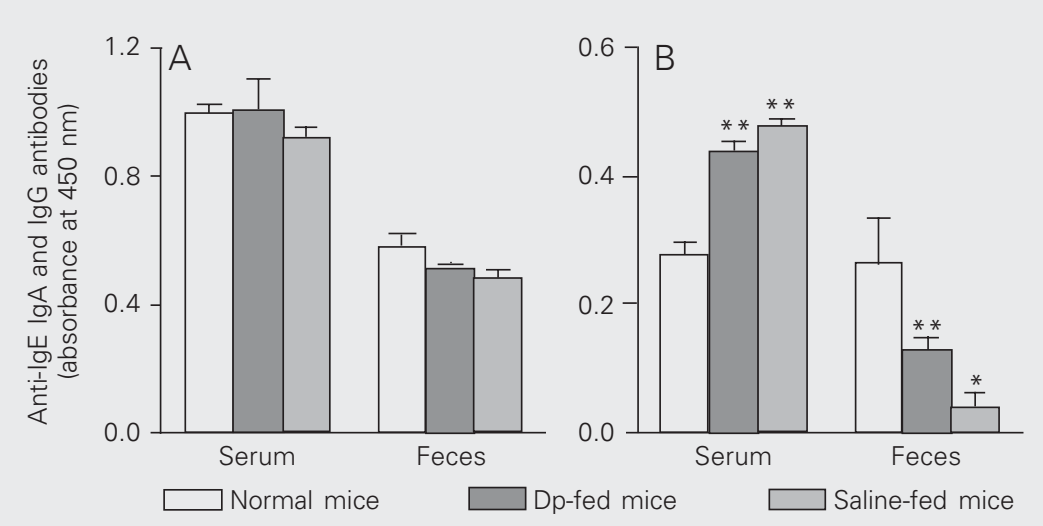

Figure 6. Determination of anti-lgE $\lg A$ and $\lg G$ antibodies in serum and feces. Sera and fecal extracts obtained from mice fed a Dermatophagoides pteronyssinus (Dp) and from saline-fed mice on the 28th day post-immunization (dpi) were assayed for IgA against the IgE molecule (anti-Dansyl, $\kappa$ chain) (A) or for IgG against the IgE molecule (B). Data are reported as means \pm SEM for 3-5 mice in each group of four independent experiments. ${ }^{*} \mathrm{P}$ $<0.05$ compared to mice fed the Dp extract; ${ }^{*} P<0.05$ compared to normal mice (unpaired Student $t$-test). have affected mainly $\operatorname{Ig} \mathrm{A}^{+} \mathrm{B}$ cells, since high total IgA antibody levels and normal IgG antibody concentration were found in feces of the groups fed the Dp extract. Challacombe $(1,12)$ and others $(17)$ have demonstrated experimentally that oral administration of antigens can stimulate IgA precursor cells in Peyer's patches and consequently IgA antibody production at the mucosal level. Our results showed that, in spite of the increased serum anti-Dp IgA levels and the enrichment of IgA-secreting cells in MLN, no disturbance of anti-Dp IgA antibody levels in fecal extracts occurred in the mice fed the $\mathrm{Dp}$ extract. It has been demonstrated that it is necessary to use a mucosal adjuvant in order to induce a consistent specific secretory IgA response $(18,19)$ and that prior oral tolerance induction suppresses the cholera toxininduced mucosal IgA responses (18). Other factors, such as antigen dose, seem to be important in the regulation of the IgA response since it was shown that mice orally treated with high doses of dinitrochlorobenzene are able to reduce the systemic and mucosal response, while low dose administration suppresses only the mucosal response (17).

The increased levels of total secretory IgA antibodies in mice fed the Dp extract indicate the involvement of polyreactive antibodies, which are considered to have a defense function against external pathogenic invasion and to provide a platform for antigen-specific immune responses. B-1-secreting cells known to synthesize polyreactive antibodies $(7,13)$, including the IgA isotype, might have been stimulated by ip Dp boosters in both mouse groups. The migration of these cells to mucosal sites may result in the increment of secretory IgA antibody observed in Dp-immunized mice, considering that most gut plasma cells come from precursors in the peritoneal cavity (20). The profile of polyreactive $\operatorname{IgA}$ antibodies against a panel of antigens, such as HEL, IgE, PC, and LPS, in mice orally fed the Dp extract remained 
unaffected. Interestingly, serum and secretory levels of anti-OVA and secretory antissDNA IgA antibodies were increased in the mice fed the Dp extract. It was demonstrated that most of the specificities of monoclonal IgA antibodies secreted by hybridomas obtained from Peyer's patches were able to recognize more than one antigen. DNA and OVA were the antigens most frequently recognized by these polyreactive IgA antibodies (6).

Furthermore, cytokines such as TGF- $\beta$ broadly act in the stimulation of mucosal IgA-secreting cells and in the maintenance of secretory polyreactive antibody production. Our previous data demonstrated increased TGF- $\beta$ basal secretion levels by mesenteric lymph nodes (11), as well as by spleen cells in mice fed with the Dp extract (16). In the present study, a decreased IFN- $\gamma$ production by peripheral lymph node cells was observed four days after Dp extract feeding. This result was obtained with both antigen and mitogen stimuli and could represent a nonspecific effect triggered by oral antigen administration in primed mice. In contrast, IFN- $\gamma$ did not directly affect the secretory IgA response (21), but antagonized the TGF- $\beta$ secretion at the mucosal level $(22,23)$. While the former has pro-inflammatory activities, the latter is a non-inflammatory cytokine and can stimulate IgA secretion (24). Furthermore, the decreased IFN$\gamma$ levels in the draining lymph nodes of mice fed the Dp extract may contribute to the remarkably high IL-10 levels found in gutassociated lymphoid tissue. TGF- $\beta$ secretion and IL-10 levels may represent factors that stimulated the IgA secretory response in mice fed the Dp extract. In contrast to serum IgA levels, those observed in fecal extracts seem to be composed essentially of polyreactive IgA antibodies, not demonstrated for all self and non-self antigens tested in the panel, but do not exclude other antigens. This supports the view that oral tolerance may induce a specific regulation of the $\operatorname{IgE}$ response in parallel to a nonspecific control of the IgA secretory response.

Autoantibodies that are capable of recognizing effector molecules of type I allergic reactions, such as IgE may also contribute to the regulation of the allergic response (2527). The concept of IgA polyreactivity was reinforced by the high reactivity of serum and secretory anti-IgE IgA antibodies detected in mice fed the Dp extract, in salinefed mice, and in control mice. Anti-IgE IgG antibody reactivity in serum was induced by immunization in mice fed or not the Dp extract, in contrast to lower levels in fecal extracts in both mice fed with Dp extract and saline-fed mice. A possible explanation could be that these autoantibodies circulate as immune complexes avoiding transudation to the intestinal lumen. Anti-IgE autoantibodies may possibly represent an additional regulatory mechanism of the $\mathrm{IgE}$ response in mice fed the Dp extract (28).

Our data showed that administration of the oral Dp extract to mice previously sensitized with it leads to a differential effect on the antibody response, decreasing the $\operatorname{IgE}$ response and stimulating the $\operatorname{IgA}$ response. The maintenance of a natural polyreactive IgA response in the serum and mucosa oral tolerant mice suggests the preservation of the physiological mechanisms of defense in the gut.

\section{Acknowledgments}

We are grateful to Raquel Guedes Silva for excellent animal care, and to Dr. Waltraut H. Lay and Miss Claudia Costabile for revising the manuscript. 


\section{References}

1. Challacombe SJ \& Tomasi TB (1980). Systemic tolerance and secretory immunity after oral immunization. Journal of Experimental Medicine, 152: 1459-1472.

2. Quan CP, Berneman A, Pires R, Avrameas S \& Bouvet JP (1997). Natural polyreactive autoantibodies as a possible barrier to infection in humans. Infection and Immunity, 65: 3997-4004.

3. Avrameas S (1991). Natural autoantibodies: from "horror autotoxicus" to "gnothi seauton". Immunology Today, 12: 154-159.

4. Guilbert B, Dighiero G \& Avrameas S (1982). Naturally occurring antibodies against nine common antigens in human sera. I. Detection, isolation, and characterization. Journal of Immunology, 128: 2779-2787.

5. Bendtzen K, Svenson M, Jonsson V \& Hippe E (1990). Autoantibodies to cytokines - friends or foe? Immunology Today, 11: 167-169.

6. Shimoda M, Inoue Y, Azuma N \& Kanno C (1999). Natural polyreactive immunoglobulin A produced in mouse Peyer's patches. Immunology, 97: 9-17.

7. Kroese FG, De Waard R \& Bos NA (1996). B-1 cells and their reactivity with the murine intestinal microflora. Seminars in Immunology, 8: 11-18.

8. Craig SW \& Cebra JJ (1971). Peyer's patches: an enriched source of precursors for IgA-producing immunocytes in the rabbit. Journal of Experimental Medicine, 134: 188-200.

9. Lamm ME (1976). Cellular aspects of immunoglobulin A. Advances in Immunology, 22: 223-290.

10. Garside P \& Mowat AM (2001). Oral tolerance. Seminars in Immunology, 13: 177-185.

11. Maciel M, Fusaro AE, Duarte AJS \& Sato MN (2000). Modulation of IgE response and cytokine production in Peyer's patches and draining lymph nodes in sensitized mice. Journal of Interferon and $\mathrm{Cy}$ tokine Research, 20: 1057-1063.

12. Challacombe SJ, Rahman D, Jeffrey $H$, Davis SS \& O'Hagan DT (1992). Enhanced secretory IgA and systemic IgG antibody responses after oral immunization with biodegradable microparticles containing antigen. Immunology, 76: 164-168.

13. Mota I \& Wong D (1969). Homologous passive cutaneous anaphylaxis in the mouse. Life Sciences, 8: 813-820.

14. Bao S, Beagley KW, Murray AM, Caristo V, Matthaei KI, Young IG \& Husband AJ (1998). Intestinal IgA plasma cells of B1 lineage are IL5 dependent. Immunology, 94: 181-188.

15. Sato MN, Carvalho AF, Silva AO, Maciel M, Fusaro AE \& Duarte AJS (1999). Low dose of orally administered antigen down-regulates the $T$ helper type 2-responses in a murine model of dust mite hypersensitivity. Immunology, 98: 338-344.

16. Sato MN, Fusaro AE, Victor JR, Oliveira CR, Futata ET, Maciel M, Carvalho AF \& Duarte AJS (2001). Oral tolerance induction in Dermatophagoides pteronyssinus-sensitized mice induces inhibition of
IgE-response and up-regulation of TGF-ß secretion. Journal of Interferon and Cytokine Research, 21: 827-833.

17. Oliver AR \& Silbart LK (1998). Local and systemic tolerance to orally administered dinitrochlorobenzene is not broken by cholera toxin. International Archives of Allergy and Immunology, 116: 318-324.

18. Kato H, Fujihashi K, Kato R, Yuki $Y$ \& McGhee JR (2001). Ora tolerance revisited: prior oral tolerization abrogates cholera toxininduced mucosal IgA responses. Journal of Immunology, 166: $3114-$ 3121.

19. Fujihashi K, Kato H, Van Ginkel FW et al. (2001). A revisit of mucosal IgA immunity and oral tolerance. Acta Odontologica Scandinavica, 59: 301-308.

20. Kroese FG, Butcher EC, Stall AM, Lalor PA, Adams S \& Herzenberg LA (1989). Many of the IgA producing plasma cells in murine gut are derived from self-replenishing precursors in the peritoneal cavity. International Immunology, 1: 75-84.

21. Kjerrulf M, Grdic D, Ekman L, Schon K, Vajdy M \& Lycke Y (1997). Interferon- $\gamma$ receptor-deficient mice exhibit impaired gut mucosa immune responses but intact oral tolerance. Immunology, 92: 6068.

22. Seder RA, Marth T, Sieve MC, Strober W, Letterio JJ, Roberts AB \& Kensall BJ (1998). Factors involved in the differentiation of TGF-ßproducing cells from naive CD4+ $T$ cells: IL-4 and IFN- $\gamma$ have opposing effects, while TGF-ß positively regulates its own production. Immunology, 160: 5719-5728.

23. Strober W, Kelsall B, Fuss I, Marth T, Ludviksson B, Ehrhardt R \& Neurath M (1997). Reciprocal IFN- $\gamma$ and TGF- $\beta$ responses regulate the occurrence of mucosa inflammation. Immunology Today, 18: 61-64.

24. Richman LK, Graeff AS, Yarchoan R \& Strober W (1981). Simultaneous induction of antigen-specific IgA helper T cells and IgG suppressor T cells in the murine Peyer's patch after protein feeding. Journal of Immunology, 126: 2079-2083.

25. Magnusson CG (1995). Major differences in specificity among naturally occurring human IgG-subclass anti-lgE autoantibodies. Journal of Allergy and Clinical Immunology, 95: 1011-1019.

26. Inganas M, Johansson SGO \& Bennich H (1981). Anti-lgE antibodies in human serum: occurrence and specificity. International Archives of Allergy and Applied Immunology, 65: 51-61.

27. Stadler BM, Stampfli MR, Miescher S, Furukawa K \& Vogel M (1993). Biological activities of anti-lgE antibodies. International Archives of Allergy and Applied Immunology, 102: 121-126.

28. Sato MN, Carvalho AF, Silva AO, Maciel M, Fusaro AE \& Duarte AJS (1998). Oral tolerance induced to house dust mite extract in naive and sensitized mice: evaluation of immunoglobulin $\mathrm{G}$ anti-immunoglobulin E autoantibodies and IgG-lgE complexes. Immunology, 95: 193-199. 